\title{
Un acercamiento a los lectores de las publicaciones de la Secretaría de Educación Pública, 1921-1934
}

\author{
An Approach to the Readers of \\ the Publications of the Ministry \\ of Public Education, 1921-1934
}

Francisco Javier Rosales Morales

Departamento de Investigaciones Educativas,

Cinvestav

fjrosales@cinvestav.mx

javvvier17@hotmail.com

\begin{abstract}
Resumen
En este artículo ${ }^{1}$ examino los discursos sobre la lectura de una selección de trabajadores (obreros, comerciantes y de diversos oficios) surgidos en el marco de la política educativa de la Secretaría de Educación Pública (SEP) desde su fundación, en 1921, hasta antes de la implantación de la educación socialista durante el cardenismo. Para ello, es importante señalar los cambios y continuidades en la política educativa, pues determinaron la producción, los contenidos y la distribución de materiales impresos: libros, revistas, manuales y folletos que formaban los acervos de las bibliotecas populares. No obstante, el objetivo principal es mostrar las formas en que los lectores se relacionaron con la cultura impresa. Busco contribuir a la historiografía de la lectura en México, no solamente a partir del estudio de la producción de materiales y el diseño de políticas editoriales, sino también —al ubicar a lectores en situaciones históricas concretas - con el análisis de la recepción y consumo de los bienes culturales.
\end{abstract}

Palabras clave: historia de la lectura, apropiación, políticas editoriales, México posrevolucionario.

\footnotetext{
${ }^{1}$ Este artículo es un producto parcial de mi tesis de maestría en el Departamento de Investigaciones Educativas del Cinvestav, en proceso, bajo la dirección de la Dra. Eugenia Roldán Vera. La investigación contó con el apoyo de una beca del Conacyt.
} 
Abstract

\begin{abstract}
This article analyzes the social discourses about reading in post-revolutionany Mexico in the framework of the educational reforms of 1921-1934. In particular, I examine the reading practices expressed in testimonials by members of the working class. I pay attention to the interruptions and continuities on educational policies of the Ministry of Education, since they determined the production, contents and distribution of books, magazines, manuals and pamphlets for popular libraries. However, the main purpose is to show the different ways in which readers appropriated the print culture.
\end{abstract}

Keywords: history of reading, appropriation, publishing policies, posrevolutionary Mexico.

\title{
Introducción
}

Los proyectos editoriales de la Secretaría de Educación Pública (SEP) en el México posrevolucionario han sido ampliamente estudiados. Algunos de esos estudios se han limitado a la labor editorial en los años de Vasconcelos al frente de la SEP (Aguirre Beltrán, 2002; Curiel Defossé, 2011; Fell, 2009; Garciadiego, 2011; Montes de Oca, 2004; Rodríguez Gallardo, 2015; Sametz, 2009); otros, a las revistas publicadas por la SEP durante el gobierno de Calles y el Maximato (Palacios, 1999; Ruiz Lagier, 2013) y algunas investigaciones han analizado los cambios y continuidades de este periodo más amplio (Loyo, 1999, 2004 y 2012; Quintana, Villegas y Tolosa, 1988; Vaughan, 1997). El estudio del fenómeno de la lectura ha sido realizado por medio de la noción del lector implícito de las publicaciones, o a través de las figuras de los editores y escritores; sin embargo, es necesario incorporar a la investigación a los sujetos a quienes estaba dirigida la educación (Loyo, 2004).

En un intento de incorporar en planos muy específicos a estos lectores se encuentra el estudio de Laura Giraudo (2004) sobre las bibliotecas para indígenas y campesinos en Puebla y Veracruz, así como el de Elsie Rockwell (2004), quien investigó las prácticas culturales en Tlaxcala a partir de los libros de texto para el periodo de 1900 a 1935. Ambas autoras llegan a conclusiones similares. Giraudo afirma que "existió una distancia entre el público imaginario de los proyectos nacionales y el público real de las comunidades campesinas e indígenas" (Giraudo, 2004: 323); Rockwell, por su parte, habla incluso de un rechazo generalizado debido a la desconfianza de la población a la cultura escrita, a un conocimiento "demasiado libresco" (Rockwell, 2004). Conviene recordar las altas tasas de analfabetismo de la época, cercanas a 80\%, y el escaso acceso a los materiales impresos, lo que puede dar cuenta de ese desinterés, así como el hecho de que los habitantes de comunidades indígenas y campesinas dieran una valoración positiva a la oralidad sobre lo escrito. 
Con todo, más allá de este aparente rechazo o desdén por los libros, otras dinámicas y procesos de apropiación lectora pueden ser contados. Aunque la abundante producción de libros, revistas y periódicos en el periodo posrevolucionario hacen del estudio de la recepción de la cultura impresa una empresa enorme, ${ }^{2}$ este trabajo se centra en un corpus limitado: la revisión de la serie documental Solicitudes y donaciones de libros perteneciente al Archivo Histórico de la SEP. Dicha serie se compone de cartas enviadas a la SEP por personas de diversos sectores y regiones del país para requerir una pequeña biblioteca; en algunas de ellas se hallan los motivos que mueven a estos actores a pronunciarse y que permiten identificar rasgos de una práctica: el porqué se leía dentro de un ámbito específico, así como las variadas disposiciones hacia el libro. ${ }^{3}$ Esto se contrastará con otros discursos sobre la lectura de los intelectuales adscritos a la empresa educativa oficial, en artículos publicados en la revista de la SEP, El Libro y el Pueblo (1922-1925), y en discursos y memorias, entre otros materiales; es decir, en este artículo se analiza tan solo una porción de la recepción y apropiación de la cultura impresa: la de los trabajadores, principalmente de medios urbanos, de las publicaciones de la SEP. ${ }^{4}$

Como sustento teórico-metodológico recupero los conceptos de apropiación y comunidades de lectores de los trabajos de Roger Chartier sobre historia del libro y la lectura (2000; 1994). La apropiación consiste en la aceptación de los mensajes y modelos emanados de los productores de normas y discursos, pero que siempre se realiza a través de arreglos, desvíos, nuevos empleos singulares que le otorgan los receptores de tales prescripciones ( $c f$. Chartier, 1994: 54). De Elsie Rockwell (2001) utilizo también la noción de creencias sobre la lectura: "en cada época o ámbito, ciertas creencias y opiniones han orientado a los lectores hacia el valor potencial de la letra impresa y moldeado el acto de leer" (Rockwell, 2001: 16-17). Así, indago, en las solicitudes de libros, cuáles eran estas creencias sobre la lectura que pervivían en los trabajadores. Esto es importante en cuanto que tales creencias permiten ver cómo las prácticas culturales presuponen continuidades y rupturas en las maneras de leer, en las formas en que los sujetos se relacionan con los materiales impresos y en el sentido que le atribuyen a los textos.

\footnotetext{
2 El artículo de Engracia Loyo (1999) sobre la lectura en el México posrevolucionario (1920-1940) menciona algunas tendencias generales del periodo. Sin embargo, su mismo carácter sintético lo hace más un trabajo introductorio que el producto de un análisis acabado sobre las implicaciones culturales, sociales y políticas de las prácticas lectoras

${ }^{3}$ El número de cajas con solicitudes de libros es de 200, aproximadamente. Cada caja contiene de 80 a 120 expedientes de solicitudes. Para la investigación seleccioné solamente 360 expedientes de acuerdo con el criterio señalado. Este texto está construido sobre una base de 217 solicitudes de trabajadores

${ }^{4}$ En la tesis analizo también las apropiaciones de la cultura impresa en escuelas: solicitudes de estudiantes, maestros y padres de familia. En ambos casos, contexto escolar y extraescolar, utilizo además solicitudes e informes de bibliotecarios, inspectores de la SEP y presidentes municipales.
} 
En el trabajo presentaré, primero, un panorama de los proyectos editoriales de la SEP y sus cambios de 1921 a 1934, para luego examinar cómo los lectores respondieron ante estos cambios. La discusión está centrada en torno de la publicación de los Ilamados "Clásicos" de Vasconcelos; argumentaré que es posible distinguir tres disposiciones del público trabajador respecto a estos libros: la primera es de una indiferencia o rechazo, al asumir que esos libros no son adecuados para ellos, y reclama otro tipo de lecturas; la segunda es la de una valoración positiva de esos libros, si bien los lectores afirman sólo poder llegar a apreciarlos en su justa medida de manera gradual, con lecturas previas más sencillas; la tercera disposición puede considerarse en el término "bourdieano" de distinción: hay lectores que se diferencian de otros porque ellos sí son capaces de apreciar el justo valor de la literatura; por lo tanto, solicitan los Clásicos de Vasconcelos. Finalmente, dedico un apartado a las peticiones e intereses de lectores de asociaciones femeninas.

\section{Las políticas editoriales de la SEP: de los "Clásicos" a los "libros útiles"}

Aun antes de la fundación de la Secretaría de Educación Pública, el que sería su primer mandatario, José Vasconcelos, ambicionaba que la política educativa fuera un proyecto cultural de nación. Junto con algunos de sus compañeros y discípulos del Ateneo de la Juventud diseñó un proyecto editorial para establecer y enriquecer bibliotecas por todas partes: escuelas pero también centros de trabajo.

Vasconcelos consideraba un departamento de publicaciones que no sólo se ocupara de difundir los progresos en la labor educativa, sino también de imprimir literatura para el pueblo, así como otras obras de temas más generales (historia, sociología, economía). Así lo señaló ante los diputados cuando presentó el proyecto de ley sobre la creación de una secretaría de educación de orden federal, bajo la siguiente precaución: "A efecto de evitar que el Gobierno se aproveche del enorme poder que llegará a adquirir esta planta editorial, la ley contiene la prohibición de que en ella se impriman obras de política militante" (Vasconcelos [1920], citado en Fell, 2009: 23).

Vasconcelos contó con el apoyo del gobierno y los recursos financieros para llevar a cabo un proyecto editorial de grandes proporciones, aunque de breve duración, que incorporaba una visión estética de la práctica lectora para un público popular. La SEP publicó este tipo de libros "esenciales" en la colección llamada Clásicos, la cual en su núcleo básico estaba formada por diecisiete obras: ${ }^{5}$ Homero, la lliada (2 vols.) y la Odisea; Esquilo, Tragedias; Eurípides, Tragedias; 
Dante, La divina comedia; Platón, Diálogos (3 vols.); Plutarco, Vidas paralelas (2 vols.); los Evangelios; Romain Rolland, Vidas ejemplares; Plotino, las Enéadas (selección); Tolstoi, Cuentos escogidos; Tagore, Obras escogidas; Goethe, Fausto. ${ }^{6}$

Asimismo, el Departamento Editorial publicó las recopilaciones de la literatura universal hechas por Gabriela Mistral, Lecturas para mujeres, y las versiones infantiles, Lecturas clásicas para niños (2 vols.), realizadas por escritores como Carlos Pellicer, Julio Torri y Gabriela Mistral. También editó dos libros de texto: el Libro nacional de lectura y escritura y la Historia patria de Justo Sierra. Así como un manual: el Método de dibujo: tradición, resurgimiento y evolución del arte mexicano de Adolfo Best Maugard.

En enero de 1921 empezó la publicación de los Clásicos con un primer tiraje de 20000 a 25000 ejemplares. Los libros no eran sólo para su distribución gratuita, también se vendían y aparentemente muy bien. ${ }^{7}$ Sin embargo, esta política editorial no tuvo continuidad en años posteriores, cuando la tendencia fue publicar y repartir folletos y manuales, dejando a la literatura de lado. Con la rebelión delahuertista, en 1924, se dio un importante recorte al presupuesto de la SEP, que repercutió en las labores del Departamento de Bibliotecas, órgano encargado de la distribución de libros en las escuelas. Posteriormente, bajo el gobierno de Plutarco Elías Calles (1924-1928) y durante el Maximato (1928-1934) los recursos destinados a dicho Departamento continuaron disminuyendo progresivamente (Quintana, Villegas y Tolosa, 1988). Mientras que la importancia dada por Vasconcelos a la creación de bibliotecas populares quedó relegada de la política educativa, las misiones culturales y la educación rural, planteadas igualmente en el periodo de Vasconcelos, continuaron siendo parte central del discurso y de las acciones emprendidas por la SEP.

Para el presidente Calles la educación debería estar al servicio directo del progreso material y, por ende, social. La veta pragmática de una educación así entendida casaba bien con las propuestas pedagógicas de John Dewey sobre la escuela de la acción. Estas concepciones y procedimientos fueron introducidos al país gracias a las visitas que profesores comisionados por la Secretaría pudieron realizar a Estados Unidos a partir de 1923. De este modo, Moisés Sáenz, subsecretario de Educación en el periodo de Calles, hizo de esa doctrina la médula para la escuela rural mexicana. Su propuesta pedagógica incluía el abandono de la memorización y los horarios fijos. Los estudiantes aprenderían a partir de actividades grupales relacionadas con su entorno: jardinería, cuidado de animales, fabricación de artesanías.

\footnotetext{
${ }^{6}$ La selección de estas obras correspondía no sólo a los gustos de Vasconcelos sino a la de su generación ateneísta (sobre los intereses y prácticas de lectura de este grupo véase Quintanilla, 2002).

${ }^{7}$ Efectivamente, de acuerdo con el Boletín de la SEP: "Las tiradas han sido de 20000 ejemplares en cada una de las obras siguientes: Ilíada, Odisea y Tragedias de Esquilo; y de 25000 las Tragedias de Eurípides, la Divina comedia y los Diálogos de Platón" (Boletín, 1922: 320). El costo de producción fue de 0.94 centavos por libro, lo que permitió fijar el precio de venta en un peso. Si bien, como observa Fell, se trató de una edición no lucrativa pues la mayoría de los libros fueron donados para la formación de las bibliotecas públicas (Fell, 2009: 489).
} 
En estas escuelas "los textos eran opcionales, excepto en las clases de historia y geografía. Los alumnos debían ser activos y el maestro un 'guía pasivo'" (Vaughan, 1997: 83).

En el programa de la SEP, el papel de la lectura también cambió. Las autoridades privilegiaban la actividad por sobre las ensoñaciones librescas, por lo que la promoción de bibliotecas pasó a segundo término. Puig Casauranc, secretario de Educación de 1924 a 1928, reconocía este distanciamiento con el proyecto vasconcelista al establecer límites a "las grandes concepciones espirituales y culturales" con las que había nacido la SEP en 1921 (citado en Barbosa, 1972: 179). Más contundente era Ezequiel Padilla, Secretario de Educación en 1928, quien señaló:

Inundaremos los campos con folletos baratos. Quizá no tengamos el placer de mirar a un campesino fatigado, debajo de un árbol, leyendo en un espléndido libro, las disputas entre Agamenón y Aquiles (risas y aplausos); pero sí podemos hacer que lean sobre su vida cooperativa, que lean sobre los grandes acontecimientos de su país; hacerles ciudadanos de su patria; llevarles el pulso diario de la República (Padilla, 1928: 13).

Los folletos publicados por la SEP en esta época trataron de temas sencillos y prácticos: cómo cuidar a los niños, organización cooperativa, consejos y reglamentos para practicar deportes, destinados a obreros y campesinos principalmente. También en estos folletos (conocidos como Silabarios) se incluía información sobre las "cuestiones sociales de mayor importancia para el pueblo", a decir de Ezequiel Padilla. Algunos títulos de sus artículos eran: "Organización de una cooperativa campesina", "Los hacendados, los líderes y los pueblos", "La casa del campesino" y "El pueblo contra el alcoholismo". Estos artículos contenían un mensaje ideológico y en algunos de ellos se criticaba el sistema social y se proponía un nuevo orden (cf. Loyo, 1999: 279).

Ahora bien, ¿cómo respondieron los trabajadores a tales cambios? ¿Qué libros reclamaban? ¿Qué buscaban en la lectura?

\section{Lecturas útiles}

Roger Chartier sugiere que una historia de los modos de leer "debe identificar las disposiciones específicas que distinguen a las comunidades de lectores y las tradiciones de lectura. La operación supone el reconocimiento de varias series de contrastes, ante todo entre competencias de lectura" (2000: 25, itálicas agregadas). De esta manera es posible emprender esta historia de los modos de leer, enfocando el análisis en las disposiciones (en quienes valoran o niegan ciertas lecturas y por qué) y sus contrastes. La finalidad no es valorar una como 
mejor que la otra, sino entender a qué se deben cada una de las disposiciones a la lectura. Chartier señala que puede aprovecharse esta comprobación en las disposiciones de los lectores de diversas maneras: "Situando los contrastes principales que distinguen los modos de lectura; caracterizando las prácticas más populares de los lectores; prestando atención a las formulas editoriales que proponen antiguos textos a nuevos compradores, más numerosos y más humildes" (Chartier, 2000: 27).

Chartier también recomienda partir de los objetos y no de las clases sociales. Es decir, no hacer una caracterización basada en la pertenencia de clase de los lectores, sino de cómo un mismo objeto, en este caso, una biblioteca con una misma selección de libros, es apropiada por distintos lectores. Pues al ponderar solamente la clasificación socioprofesional se ha olvidado que otros criterios de diferenciación, igualmente sociales, pueden dar cuenta, y con más exactitud, de las apropiaciones culturales, tales como el género, generación, la adhesión religiosa, entre otras (Chartier, 2000: 28).

En los informes de inspectores de la SEP hay una concepción de lo que es deseable dar a los lectores según las capacidades que les atribuyen. De esa forma, en lugares donde la mayoría de la población era analfabeta debía fomentarse, después de alfabetizar, un tipo de lectura adecuada para la población, que fuera de lo más simple a lo más complejo. Así, en 1925, meses después de que Manuel Gamio hubiera reprobado en El Libro y el Pueblo la publicación de los clásicos por inapropiados y sugerido en cambio la lectura gradual, ${ }^{8}$ el informe de Elpidio López para una biblioteca en Villahermosa, Tabasco, afirmaba:

\begin{abstract}
Para los adultos tabasqueños creo que dado el clima y el gran porcentaje de analfabetos se puede conseguir que le vayan teniendo cariño a los libros, empezando por desanalfabetizarlos y luego poniendo en sus manos periódicos, diarios y revistas, así como aquellos libros que puedan entender, que están a su alcance y que satisfagan sus necesidades y de ninguna manera libros clásicos que con trabajo entienden los que tienen cierto grado de cultura?
\end{abstract}

El rechazo a los clásicos no provenía solamente de los agentes de la Secretaría. Una tendencia fuerte en las solicitudes de libros de los trabajadores, lo mismo obreros que campesinos y de otras ocupaciones, apunta a esta necesidad de la lectura utilitaria. Así, en 1924, en una segunda petición para incrementar el acervo de la biblioteca de la Unión de Calderos de

\footnotetext{
8 "En cuanto al restante, inmenso número de gentes que forman el público lector, ninguna, podemos asegurarlo, abrió las páginas de las 'Tragedias' de Esquilo y las 'Vidas Paralelas' de Plutarco, cosa natural, puesto que el conocimiento de lo clásico debe ser posterior a prolongadas y graduadas lecturas preparatorias. Proceder de otra manera sería incurrir en pedantismo y el pueblo nunca cae en ese pecado" (Camio, 1925: 15)

${ }^{9}$ Informe de Elpidio López a Esperanza Velázquez Bringas, Villahermosa, Tab., 9 de diciembre de 1925. Archivo General de la Nación, Archivo Histórico de la Secretaría Pública, Departamento de Bibliotecas (en adelante: AGN, AHSEP, DB), caja 31162, exp. 24-6-34-68. Se respeta la ortografía original de los documentos que componen esta serie.
} 
Apizaco, Tlaxcala, el obrero Delfino Torres, a nombre de sus compañeros, notaba que los libros con los que contaban les prestaban poca ayuda. Su interés en la lectura estaba puesto en mejorar, lo más posible, en su oficio:

Qué los cien volúmenes donados por esa Secretaría, son en su mayoría y casi en su totalidad obras literarias, y deseariamos, en caso de ser posible; nos fueran facilitados algunos tratados de Calderería, Hojalatería, Cobrería u otros que nos proporcionen mayores conocimientos en nuestro oficio; pués de esa manera creemos llegue a perfeccionarse el Obrero en su trabajo. ${ }^{10}$

La lectura, de esta manera, era vista por los trabajadores como un medio para ampliar sus conocimientos laborales. Otros trabajadores solicitaban obras adecuadas a sus conocimientos, incluso que estuvieran en un soporte sencillo, como los folletos y revistas que terminó propagando la SEP hacia 1928. Así lo expresan unos habitantes de Torreón, Coahuila, en 1930: "No deseamos obras de alto valor literario ni representativo si no obras que esten a nuestro alcanse y que su presentacion sea modesta". ${ }^{11}$

Asimismo, los libros sobre las problemáticas sociales eran de los más solicitados por los gremios y asociaciones laborales. A decir de una asociación de carpinteros en Pachuca, Hidalgo: "Encareciendole se nos manden de preferencia obras Sociológicas que puedan orientarnos hacerca de problemas que afectan la vida nacional, así como algún tratado de Carpintería que nos sirvan para ampliar nuestros conocimientos en el ramo". 12

Sobre este tipo de lecturas, más instructivas, el encargado de la biblioteca pública de Gómez Palacio, Durango, Antonio Rodríguez, decía:

Ahora, con motivo de tener conocimiento los lectores, que en su mayoría son obreros que concurren a las labores vespertinas y nocturnas del "Centro Cultural", de que posee esta Biblioteca buen número de obras didácticas, con bastante solicitud llegan con mucha anticipación a extractar algo de dichos libros.

Hoy veo con verdadera satisfacción que muchos abandonan la novela por estudiar "Lecciones de Cosas".13

\footnotetext{
${ }^{10}$ Carta de Delfino Torres a L. García Núñez, Apizaco, Tlax., 17 de septiembre de 1924. AGN, AHSEP, DB, caja 31162, exp. 24-6-34-122.

${ }^{11}$ Carta de Jonás de Luna a Aarón Sáenz, Torreón, Coah., 18 de julio de 1930. AGN, AHSEP, DE, caja 31029, exp. 11-7-10-147.

${ }^{12}$ Carta de Alfredo Palafox al Srio. de Instrucción Pública, Pachuca, Hgo., 31 de enero de 1926. AGN, AHSEP, DB, caja 31205, exp. 24-8-26-15.

${ }^{13}$ Carta de Antonio Rodríguez al Jefe del Depto. de Bibliotecas, Gómez Palacio, Dgo., 14 de octubre de 1922. ACN, AHSEP, DB, Caja 31269, exp. 24-5-15-4, f. 8.
} 
Sabemos más de esta biblioteca por el informe del inspector del Departamento de Bibliotecas. Contaba con 278 volúmenes en septiembre de 1922, tenía capacidad para cincuenta lectores y era ocupada en las noches por una clase del Centro de Educación a la que concurrían algunos jóvenes que durante el día trabajaban en los talleres ferrocarrileros. El horario de la biblioteca era de 9:00 a 13:00 y de 15:00 a 17:00 horas y se atendía a un promedio de 75 lectores diarios. Entre las preferencias de los lectores estaban las novelas de aventuras, en especial de la Colección Salgari, con sus historias de piratas y corsarios. ${ }^{14}$ Llama la atención que este tipo de libros son raramente solicitados a la SEP por los mismos trabajadores.

Las solicitudes de varias asociaciones obreras indican que para los trabajadores no había otro interés que la organización sindical y los conocimientos útiles propios para el mejor desempeño de sus oficios. Los intereses de lectura de las asociaciones obreras corresponden sobre todo a libros "modernos", en oposición a lo clásico que es considerado algo antiguo y de nula utilidad práctica. Para los obreros una de las disciplinas modernas era la sociología y las obras socialistas, pues hablaban de la organización y las luchas a las que debían hacer frente: "enriquecer más nuestra Biblioteca con obras que nos hablaran de Sociologia, pues como obreros estamos deseosos de leer esta clase de libros",15 también los libros que, sin mencionar una disciplina o explicitar una ideología, hablaran de temas "sociales, civiles y de derechos individuales". 16

Hasta ahora podemos ver que entre una porción de la población trabajadora efectivamente prevalece una idea de que hay lecturas que son vedadas a los lectores de acuerdo con su propia incapacidad de entenderlas, y los "clásicos" son un lujo de las élites intelectuales, "que con trabajo entienden los que tienen cierto grado de cultura". Esta concepción no tiene nada de novedoso: "El argumento que coloca a quienes tienen derecho a leer, porque pueden hacerlo 'bien' [...] frente a quienes debe negarse la lectura, porque 'no entenderían', es tan antiguo como engañoso" (Manguel, 2005: 416). Ya en la Grecia clásica, Sócrates había dicho:

Cuando una cosa se pone por escrito, el texto, sea el que fuere, se lleva de un sitio a otro y cae en las manos no sólo de aquellos que lo entienden, sino también de aquellos otros

\footnotetext{
${ }^{14}$ Informe sobre la Biblioteca Pública de Gómez Palacio, Gómez Palacio, Dgo., 26 de septiembre de 1922. AGN, AHSEP, DB, caja 31269, exp. 24-5-15-4, ff. 3-4.

${ }^{15}$ Algunos ejemplos son los del Sindicato de Tabaqueros, Puebla, Pue., 1927. AGN, AHSEP, DB, caja 31160, exp. 24-8-43-20; Sindicato de Aguas Gaseosas, Orizaba, Ver., 1926. Ibid., caja 31163, exp. 24-8-31-34; Confederación General de Trabajadores, D.F., 1926. Ibid., caja 31165, exp. 24-8-23-42; Biblioteca de los obreros de La Fama, La Fama, N.L., 1923. Ibid., caja 31272, exp. 24-5-35-56.

${ }^{16}$ Sindicato de obreros de la Fábrica "El Valor", Xicoténcatl, Tlax., 1927 AGN, AHSEP, DB, caja 31160, exp. 24-8-4392; Otros ejemplos: Sindicato de Filarmónicos "Pro Arte y Trabajo", Torreón, Coah., 1930. Ibid., caja 31029, exp. 11-710-121; Unión de Cargadores y Carreteros, Mazatlán, Sin., Ibid., caja 31234, exp. 24-9-12-63.
} 
que nada tienen que ver con él. El texto no sabe cómo dirigirse a las personas adecuadas y dejar de hacerlo a las que no lo son (citado en Manguel, 2005: 416).

Bajo esta concepción del fenómeno de la lectura, al texto le correspondería una lectura única, una sola interpretación posible que puede ser llevada a cabo por un público capaz de entender lo escrito. Esta visión establece límites y oposiciones, de acuerdo con un determinismo social, entre el público adecuado, y el que es incapaz. No obstante, "ambos estereotipos son invenciones y los dos peligrosos, porque son capa de crítica moral o social se utilizan con el fin de restringir una habilidad que, en su esencia, no es ni limitada ni limitadora. La realidad de la lectura es otra" (Manguel, 2005: 417). Además, como veremos enseguida, también entre los mismos trabajadores hubo concepciones más amplias sobre el sentido y la utilidad de la lectura.

La colección de los clásicos de la SEP había sido publicada efectivamente contra esas concepciones más limitadas de la lectura. Vasconcelos creía en la capacidad creativa de la infancia, etapa en que el peso de la pertenencia social aún no era tan determinante:

Las lecturas clásicas darán al alumno lo que a menudo la escuela le niega: la sensación de la vida en su conjunto, el drama o la gloria de un destino en proceso. A la objeción apuntada por algunos de que los niños no comprenden los clásicos, responded que una observación atenta descubre que abunda más el talento en la infancia que en el hombre. Algo de genio hay en cada niño, y sólo cuando crecemos nos vamos haciendo tontos [...] La frescura, la agilidad, la penetración, el pasmo fecundo de la primera edad ya no se recobran. Dejad, pues, que se nutra la mente joven con la esencia más alta del espíritu humano y no con desechos y con interpretaciones. Alejad al niño de lo subalterno, ya que después, por obligación, tendrá que leer tanto libro mediocre (Vasconcelos 2009 [1935]: 73).

Torres Bodet, director del Departamento de Bibliotecas de 1921 a 1924, también creía en la agencia lectora de la población, pero le preocupaba que el proyecto editorial resultase demasiado idealista, si es que tales libros realmente eran abiertos y leídos:

Temeroso de que, por falta de profesores, la función escolar no marchase al compás de nuestras distribuciones de libros, me preocupaba pensar que un reparto profuso de bibliotecas puede producir una promoción azarosa de autodidactos. ¿Qué hacían con nuestras colecciones muchos de los presidentes municipales que las habían solicitado? En no pocos lugares, un mozo, un gendarme a veces, recibía el encargo de proceder al registro de los volúmenes. En otros, un mecanógrafo -improvisado bibliotecario - alertaba a la población. Algunos vecinos se decidían a visitarle. A la admiración, sucedían los escrúpulos. ¿Cuál de todas aquellas obras sería prudente pedir en préstamo? Desfilaban títulos: La Odisea, La Divina Comedia, Vida de Miguel 
Ángel. El candidato más esforzado a lector gratuito se sentía tranquilizado por la presencia de Don Quijote. El más discreto se contentaba con un manual (Torres Bodet, citado en Quintana, Villegas y Tolosa, 1988: 173-174).

Con todo, en Torres Bodet pervivía la convicción de que los libros despedían una luz que ni los enemigos del libro podían apagar:

\begin{abstract}
Tales observaciones no llegaron jamás a desalentarme. Era imprescindible insistir. Hasta en la hoguera - pensaba yo - , ¡hasta en la hoguera donde los tiranos lo arrojan, el libro, ardiendo, desprende luz! Y ésa, si no me engaño, era la actitud espiritual que correspondía a la época que vivíamos: época de fervor y de don total, sin discrepancias y sin reservas (Torres Bodet, citado en Quintana, Villegas y Tolosa, 1988: 174).
\end{abstract}

Si, como señala Alberto Manguel, leer es una actividad que los gobernantes, los dirigentes, siempre han visto con un entusiasmo limitado (Manguel, 2011: 252), este no era el caso de los intelectuales en el Departamento Editorial y de Bibliotecas en la SEP durante el periodo de Vasconcelos. Sí lo sería con los intelectuales más pragmáticos que los sucedieron. Para Moisés Sáenz, para Ezequiel Padilla, para los maestros —intelectuales pedagogos como los denomina Palacios (1999) - que escribieron en la revista El Maestro Rural, la lectura simplemente no era tan importante. O lo era en otro sentido. Para ellos, la lectura que debía propiciarse entre campesinos y obreros estaba al servicio de fines más prácticos: aprender o mejorar sus oficios, aprender a organizarse gremial o sindicalmente - siempre con la imagen tutelar del Estado—, adquirir nociones de higiene y comportamiento moral, en fin:

\footnotetext{
El uso de lecturas y transmisiones radiofónicas cuidadosamente seleccionadas de acuerdo con lo que los intelectuales pedagogos consideraban "conveniente para los campesinos", según la representación que habían formado y comenzaban a difundir de lo que sería el papel de ese "nuevo" grupo social en el régimen posrevolucionario y, en consecuencia, el tipo y cantidad de "cultura occidental" que se le debía proporcionar para que cumpliera las metas que se le atribuían de manera unilateral (Palacios, 1999: 229).
}

Las habilidades lectoras más difíciles de alcanzar, es decir, el poder leer a profundidad, abandonarse a la lectura, "entrar en un libro y explorarlo hasta sus límites a veces inalcanzables" (Manguel, 2011: 255), que requerían de algo más que folletos informativos o de propaganda estatal para ser desarrolladas, no eran ya parte del proyecto editorial de la SEP posterior a 1924. Además, las prioridades de las políticas públicas de 1924 a 1934 estaban más encaminadas a satisfacer las demandas básicas: comida, vivienda, servicios de salud. 
Sin embargo, mientras para algunos lectores el cambio de política editorial después de 1924 fue bienvenido, otros trabajadores buscaban una forma de complementar aquellas lecturas "útiles" con el desarrollo de otras capacidades que, en su opinión, requerían de obras diferentes a las únicamente fomentadas por la SEP a la salida de Vasconcelos.

\section{Lecturas graduadas}

En mayo de 1924, Ascensión Lerma, presidente municipal de Santo Tomás, Chihuahua, solicitaba una biblioteca que fuera "propia para el proletariado". ${ }^{17}$ La biblioteca que pedía, según dijo, sería establecida a un costado de su oficina, donde él se encargaría de que prestara servicio desde las siete hasta las diecinueve horas. Unas semanas después, al recibir un total de cincuenta libros de la SEP, compuestos principalmente por una colección de clásicos, literatura hispánica y universal, así como uno que otro libro de historia y algunos tomos de enciclopedias y libros de texto, el presidente municipal preveía la utilidad que podían prestar tales libros para incrementar la cultura de la población: "Con este paso sobre base firme podemos esperar mucho, aunque primero debamos crear el gusto por lo bello. Los cincuenta volumenes comienzan a prestar sus servicios. Me sera grato informar detalladamente despues del interes que estos despierten en nuestro pueblo". 18

Desafortunadamente no se encuentra una carta posterior que informaba de la recepción de estos libros; sin embargo, la carta es importante porque anuncia una disposición positiva, aunque primero se deba "crear el gusto por lo bello". Tal forma de asociar la cultura escrita a la belleza por medio de la literatura enviada por la SEP está presente en otras solicitudes, sobre todo en las de trabajadores que conformaban grupos culturales; para ellos, el trabajo no lo era todo y buscaban también una recreación estética en sus horas libres. Así, miembros del grupo cultural "Amado Nervo", conformado por los trabajadores jóvenes de la industria textil de Río Blanco, Veracruz, señalaban en 1927:

Dentro de sus miembros y dentro del elemento estudiantil Obrero de esta localidad, que es numeroso, se ha despertado el amor y el entusiasmo por el arte de la Declamación y la Poesía, arte que hace conocer a quien lo ama y lo practica en una palabra, lo que se llama Belleza. Es por esto por lo que los Representantes del Grupo ya citado, tienen en proyecto organizar un Recital Poético, para que en éste tomen parte todos los alumnos que lo deseen, de las escuelas de la Localidad y los miembros de este grupo; nombrando para el efecto un jurado competente [...] Las intenciones de los

${ }^{17}$ Carta de Ascensión G. Lerma, Presidente Municipal, a la SEP, Santo Tomás, Chih., 31 de mayo, 1924. AGN, AHSEP, DB, caja 31256, exp. 24-6-6-96, f. 1.

18 lbid., f. 7. 
subscritos son de obsequiar como premios, no dinero que enorgullece, sino unos Libros, pero de esos que por sus pastas son humildes y modestos, pero que en su interior se encierran batallones inmensos de letras que son los que llevan a la victoria en la lucha por la vida, a los que los cuidan y a quienes los aman.19

A este tipo de peticiones la SEP respondía con el envío de la colección de los clásicos, libros que encerraban belleza y que eran dignos de ser amados, aunque a primera vista su lectura no fuera tan fácil.

Hacia 1930, el Departamento de Bibliotecas hizo una encuesta a los bibliotecarios del Distrito Federal sugiriéndoles que tomaran en cuenta la situación social y cultural del barrio en que se hallaban sus bibliotecas, usaran las estadísticas de los lectores para saber qué temas eran los más solicitados y "no perder de vista que el objeto de las bibliotecas populares es el de elevar el nivel cultural de las masas gradualmente, partiendo de aquel en que se encuentren". ${ }^{20}$ Ante tales recomendaciones, los bibliotecarios respondieron que, en general, carecían de libros de texto y de consulta que eran los más solicitados:

Constantemente ocurren a esta Biblioteca, no solamente los profesores y alumnos de las Escuelas Universitarias y Preparatorias, sino también los campesinos floricultores y agricultores a consultar sus dudas y he tenido, en muchos casos que decir a unos y otros, que no hay un solo libro de los que ellos solicitan. ${ }^{21}$

La encuesta levantada entre los bibliotecarios fue para el Departamento:

Sumamente fructuosa en resultados, pues se llegó a saber que en todos los casos más del $60 \%$ de las obras solicitadas y no existentes son libros de texto. El porciento restante lo constituyen obras generales y de especialización, complementarias o iniciadoras de una cultura que los libros de texto encausan y perfeccionan en la escuela.22

Para los bibliotecarios, la forma de mejorar gradualmente la cultura la constituía, entonces, el libro de texto y de consulta. Sin embargo, sus reportes no muestran una descripción detallada de las resistencias o prácticas de los lectores y pocos se atreven a formular más

\footnotetext{
${ }^{19}$ Carta de E. Bretón, Santiago Domínguez y Celso Centeno a Manuel Puig Cassauranc, Villa de Río Blanco, Ver., 22 de marzo, 1927. ACN, AHSEP, DB, caja 31282, exp. 24-9-8-97.

${ }^{20}$ Rafael Pérez Taylor, Jefe del DB, Circular VI-3-34: Que formulen listas de libros y pidan la adquisición de colecciones con que juzguen deben contar las bibliotecas. México, D.F., 20 de octubre, 1930. ACN, AHSEP, DE, caja 31028, exp. 11-7-9-230, f. 1 .

${ }^{21}$ Juan E. Noguez, Lista de libros que se pide, en Circular VI-3-34. Xochimilco, D.F., 24 de octubre, 1930. AGN, AHSEP, DE, caja 31028, exp. 11-7-9-230, f. 14.

${ }^{22}$ Rafael Pérez Taylor, Memorándum, México, D.F., 3 de enero, 1931. AGN, AHSEP, DE, caja 31028, exp. 11-7-9-230, f. 27.
} 
sugerencias. El encargado de la biblioteca "María Enriqueta", ubicada en el barrio de Tacuba, sí sugirió algo un tanto diferente:

Me he permitido incluir los títulos de algunas de las obras maestras de la literatura universal, contenidas en la famosa Colección Araluce, cuyos extractos están al alcance no solamente de los niños, sino también de muchos adultos carentes de la cultura necesaria para comprender y asimilar las obras clásicas de la antigüedad, si no es en la forma de síntesis que nos da esta Colección, contribuyendo al buen gusto literario. ${ }^{23}$

Para el bibliotecario, como para Vasconcelos, las Lecturas clásicas para niños eran una forma de iniciación que despertaría el interés por las versiones originales, menos accesibles para un público que apenas estaba empezando a leer. En algunos lugares se reconoce esa diferenciación entre los lectores "recién desanalfabetizados" y los que no requieren ser tratados como "niños". Estos últimos son más frecuentes en localidades que se percibían con un mayor grado de modernidad, como en Fernández Pedriceña, Durango, uno de cuyos habitantes exigía libros en cantidad y calidad acordes al nivel adquirido en su localidad:

Pues "Fernández" es ya importante centro de la región de suerte que no solo le servirá a muchos que hay allí que saben leer y que ya piensan a la moderna y que tienen necesidad de alimento espiritual a la Europea sino de todos los alderredores. Y como tenemos aspiración de constituirnos en "modelo" en nuestro Estado, queremos también nuestra biblioteca sea "modelo" y por tal razón le encarecemos atentamente a $U$. que se sirva dar ordenes para que si se nos mandan libros para la formación de nuestra biblioteca sean estos en cantidad y calidad a propósito para hacer ese "modelo" $[\ldots]$

Anexa a la biblioteca queremos tener una Exhibición Permanente de Productos Regionales para instituir despues premios para los mejores productores anualmente. Tendremos un campo de sport (hay ya novena de base-ball), Cine cooperativo, un aparato de radio, en fin queremos a la par que abrir brechas y forjar patrimonios matar el tedio y educarnos. Todo lo que necesitamos es una paz organica. ${ }^{24}$

En este ejemplo, la biblioteca es parte - junto con el cine, la radio, y la práctica de deportesde la modernización de la localidad que de a poco se va alejando de una vida donde impera el "tedio", esa característica atribuida por los intelectuales de la SEP al medio rural. De esa manera, las acciones de la SEP son vistas por los lectores como civilizadoras.

${ }^{23}$ Máximo Asenjo, Se remite lista bibliográfica de obras necesarias para esta Institución. Tacuba, D.F., 3 de noviembre, 1930. AGN, AHSEP, DE, caja 31028, exp. 11-7-9-230, f. 21.

${ }^{24}$ Carta de Fernando Garcinava a Esperanza Velázquez Bringas, Fernández Pedriceña, Dgo., 29 de enero, 1926. AGN, AHSEP, DB, caja 31240, exp. 24-6-47-44, f. 1. 


\section{Lecturas de los clásicos}

En Penjamillo de Degollado, Michoacán, los habitantes también tenían la percepción de poseer un cierto nivel de cultura gracias a la educación y a la circulación de periódicos. El solicitante de una biblioteca para los habitantes de esta localidad, Carlos Álvarez, presidente del Comité Agrario, describe algunas características de su comunidad:

Villa con más de 8.000 habitantes, perteneciente al Distrito judicial de la Piedad, Estado de Michoacán. Su población es de alguna cultura, pues ha habido siempre buenos plantes de enseñanza, tanto oficiales como de dos instituciones de beneficencia ahí establecidas. En diversas ocaciones ha exitido en dicho lugar periódico semanario. Algunos de sus hijos han figurado en la primera Magistratura del Estado y en puestos importantes..$^{25}$

Tal caracterización parecía un intento de mostrar que no se trataba de un pueblo miserable y carente de cultura, una diferenciación de la localidad respecto a los alrededores. Pero también se daba esa diferenciación respecto a los grupos sociales de un lugar. Por ejemplo, las sociedades y logias teosóficas que enriquecían sus bibliotecas con las donaciones de la SEP en Saltillo, Coahuila, podían señalar que los clásicos, denostados por los obreros y campesinos, sí eran aprovechados por ellos: "Todas las obras que Uds nos han mandado, son de verdadero merito filosófico, esta sociedad cuenta con algunos Masones y Teosofistas, por lo que podemos asegurar que los libros con que cuenta nuestra biblioteca no duermen recopilados como sucede en otras partes". ${ }^{26}$ De igual forma, en su solicitud de una colección de los clásicos a Vasconcelos, en 1924, Humberto Schleske, quien decía haberse desempeñado como profesor de la Escuela Superior de Niñas del Estado y del Colegio Preparatorio de Veracruz, al enterarse que a un centro comunista le habían donado tales libros advierte que él también es merecedor de tener esa colección por ser un amante de los libros: "Yo amo más un buen libro, que un vil peso, colocando los libros en el lugar de honor de mi pobre estante, no como otros los tienen, en la última tabla del último cuarto como si fuesen papeles viejos, todos Ilenos de plumilla, y en lugares donde cae gotera". ${ }^{27}$ Para que no hubiera duda de la importancia que le daba a los libros, el señor Schleske no sólo se refiere al lugar privilegiado donde los ha de colocar, sino a su animosa lectura:

\footnotetext{
${ }^{25}$ Carta de Jesús Ramírez a Esperanza Velázquez Bringas, Penjamillo de Degollado, Mich., 8 de junio, 1925. AGN, AHSEP, DB, caja 31214, exp. 24-7-27-10.

${ }^{26}$ Carta de Ignacio Rodríguez a la SEP, Saltillo, Coah., 10 de septiembre, 1924. ACN, AHSEP, DB, caja 31257, exp. 24-6-5-41.

${ }^{27}$ Carta de Humberto Schleske a José Vasconcelos, Ministro de Educación Pública, Veracruz, Ver., 4 de junio, 1924. AGN, AHSEP, DB, caja 31207, exp. 24-6-22-32, f. 1.
} 
Yo tenía muchos deseos de conseguirme todas estas obras [...] y al llegarme me he puesto loco de contento, hasta la gana de comer se me quitó, como le pasa a los muchachos cuando reciben un juguete, que la emoción les quita hasta el sueño. Estas obras son haz de perlas, son un primor, es expléndido todo esto, y hay quitarse el sombrero. Ya leí las tragedias de Esquilo, y sigo con Eurípides, yo no las conocía, son un encanto, su moral, su filosofía, su poesía, no hay palabras para ponderarlas [...] en seguida que las recibí, las coloqué en mi estante, con cuidado y celo, como se conservan las cartas de los enamorados $\left[\ldots . .{ }^{28}\right.$

Como se ha observado en algunas investigaciones sobre prácticas lectoras en sectores marginados y donde se cree abundan los "poco lectores" (Bahloul, 2013; Peroni, 2003), a los libros expuestos en las salas se les atribuye un valor simbólico, hacen las veces de puntos de referencia social o de reivindicadores de distinción social. Más aún, estas maneras de relacionarse con los soportes textuales dicen mucho sobre la práctica lectora: "Por ello no hace falta saber cuántos libros posee cada lector, sino más bien cómo los adquirió y qué destino les reserva después de haberlos adquirido" (Bahloul, 2013: 75). En la carta de nuestro lector se dan respuestas a ambas interrogantes: para él, la cuestión no era sólo adquirir esos libros; su entusiasmo al recibirlos lo animó a escribir otra carta de agradecimiento donde indicó que ya había leído al menos un libro de la colección, y que dichas obras estarán presentes en su vida diaria al colocarlos en su sala principal.

Por otra parte, se puede encontrar una reacción de los integrantes de la Alianza de Ferrocarrileros Mexicanos de la sucursal de San Luis Potosí contraria a los preceptos del secretario de Educación, Ezequiel Padilla, quien, en 1928 se había pronunciado por economizar los recursos destinados a las publicaciones de la SEP y de editar mayoritariamente folletos con información útil para los trabajadores. Consciente de que tal vez no recibirían más libros sino sólo aquellos folletos más "adecuados" para ellos; uno de los trabajadores, Elías Terán, "inspirado por un rasgo de atrevimiento", ${ }^{29}$ le escribió directamente a Padilla para señalar su desacuerdo sobre aquello que debían leer:

La Alianza [... se ha propuesto a que su elemento no se concrete a trabajar únicamente como una bestia humana, ni que las Sociedades persigan únicamente fines socialistas, sino que estamos buscando la manera de iluminar algo nuestros cerebros

\footnotetext{
${ }^{28}$ Carta de Humberto Schleske a Jaime Torres Bodet, Jefe del Depto. de Bibliotecas, Veracruz, Ver., 20 de junio, 1924. AGN, AHSEP, DB, caja 31207, exp. 24-6-22-32, f. 7.

${ }^{29}$ La carta de Elías Terán a Ezequiel Padilla empieza así: "Inspirado por un rasgo de atrevimiento tal vez señor Padilla, y a la vez por el entusiasmo que produjo su pieza oratoria pronunciada con motivo de la inauguración del año universitario, decidí dirigirle la presente, con objeto de inferirle una molestia, ínfima para usted, pero de mucha utilidad para la clase oprimida, o sea para el elemento trabajador". Carta de Elías Terán a Ezequiel Padilla, San Luis Potosí, S. L. P., 22 de febrero, 1929. AGN, AHSEP, DB, Caja 31178, exp. 24-9-24-112.
} 
y para ello y con motivo de esta campaña [...] acordamos que esta Sucursal formara una biblioteca, para lo cual exigimos un libro a cada socio. ${ }^{30}$

Estos trabajadores buscaban conformar una biblioteca que fuera un orgullo para sus miembros y que perdurara como un legado, que no incluyera sólo lecturas acorde a esos fines ideológicos que se les atribuían unilateralmente por parte de la SEP en sus nuevas políticas editoriales.

Ya para la época cardenista no quedaban rasgos del primer impulso editorial ateneísta. No obstante, es interesante observar cómo un lector de Cuetzala del Progreso, Guerrero, consciente de su desubicación, solicita, en 1937, una colección de los clásicos:

En virtud de tener verdaderas ansias de conocer algo sobre las civilizaciones y culturas pasadas sin poseer recursos económicos para comprar las obras necesarias para leer, y teniendo conocimiento de que la Secretaría de Educación editó hace pocos años muchos libros de literatura clásica y los distribuyó entre los interesados [...] Aclaro a Ud. que en los presentes momentos de profunda agitación y atención para los problemas sociales de más actualidad quizás pudiera juzgarse como extemporánea la solicitud de los libros a que arriba me refiero. Pero es el afán de tener un conocimiento seguro de los hechos pasados para concebir perfectamente los presentes, que me induce a hacerlo. ${ }^{31}$

Por otro lado, algunos grupos expresan la creencia en el poder transformador del libro. Los obreros sindicalizados de ciudad Camargo, Chihuahua, en 1930, esperaban progresar a partir de la lectura no sólo en términos materiales:

El suscrito Comité Ejecutivo de esta Unión, considerando como uno de sus altos deberes procurar la elevación moral e intelectual, aparte de la material, ha creido hayar un medio eficaz para el desempeño de este deber y logro de su más sincero y anhelante propósito: El Libro. Es indudable que el libro ha sido siempre un agente poderoso de la civilización. "Los pueblos que más leen son los pueblos que más saben", ha dicho un escritor; $y$ esto se demuestra a las claras en un curiosos y reciente informe estadístico que fué publicado con respecto a las Bibliotecas con que cuenta cada país y en el cual se destaca en primer y envidiable lugar la culta nación alemana, quedandose, desgraciadamente, muy atrás nuestro país en ese sentido. Dos cosas, entre otras, son las que distinguen a nuestra patria y son: el ridículo número de bibliotecas públicas que existen y la terrible aversión que siente nuestro pueblo hacia el Libro. Queda, pues, a los hombres de buena voluntad de la presente y futuras generaciones, a los

${ }^{30}$ Ibid., caja 31178, exp. 24-9-24-112.

${ }^{31}$ Carta de Catalino Gutiérrez al Jefe del Depto. de Bibliotecas, Cuetzala del Progreso, Gro., 10 de noviembre, 1937. ACN, AHSEP, DB, caja 31229, exp. 17-8-4-320. 
verdaderos revolucionarios que desean el despertar del pueblo, de ese pueblo andrajoso y miserable que tan explotado y vilipendiado ha sido por tantos años y que todavía la reacción se obstina en mantener a obscuras, a esos hombres amantes de la libertad y del progreso, repetimos, quedan sobre sus espaldas dos tareas que hacer: multiplicar indefinidamente los centros de lectura y hacer que nazca en nuestro pueblo la inclinación y el amor a los libros. Cuando esto se haya logrado nuestra patria será grande, culta y respetada. ${ }^{32}$

Para estos obreros, la biblioteca reviste ese carácter de agente modernizador y es el medio para alcanzar una cultura que les gane el respeto de los demás. Algo parecido a lo que les sucedió a los habitantes de Fernández, Durango, quienes aspiraban alcanzar una "paz orgánica" gracias a la lectura, el cine, la radio y los deportes que los alejaran del tedio. En aquella localidad, donde algunos ya pensaban "a la moderna y tenían necesidad de alimento espiritual a la europea", como en ciudad de Camargo, se ilustra una de las manifestaciones más peculiares del proceso civilizatorio respecto a las clases ascendentes:

En este proceso sucede a menudo, si no siempre, que estas clases se transforman por el hecho de que las personas de la clase alta poseen una educación superior, por lo que aquéllas se sienten impresionadas por su inferioridad social, por el conjunto de prohibiciones, la regulación de los afectos y el código de comportamiento de la clase alta, de modo que tratan de orientar su propia regulación emotiva según el esquema de ésta (Elias, 2012: 612).

Tal proceso de "aburguesamiento" es sólo una parte de la interpretación posible. El deseo de los trabajadores de leer y de "distinguirse" por el hecho de no adecuarse a las lecturas que se suponía más convenientes para ellos puede ser también una búsqueda genuina de autonomía intelectual. En los libros buscaban también una forma de comprender su mundo, encontrar belleza en la palabra escrita, conocerse a sí mismos. Aquí recobra importancia la noción interactiva de la lectura. En un artículo publicado en el Libro y el Pueblo, en 1922, Gabriel Alomar, escritor español, llama la atención sobre el gran valor de la literatura que empezaba a publicar la SEP, y sobre esa "transformación" que es capaz de realizar el libro en una persona:

El libro, en su verdadero valor, es una luz cambiante, una medida de nuestra mutabilidad y perfectibilidad, una prueba de nuestra fuerza espiritual, más intensa cuanto más hayamos podido desmentirlo o completarlo. El interés superior de un libro está en las notas marginales que escribamos en sus páginas, a modo de chispas de nuestro propio

${ }^{32}$ Carta firmada por varios trabajadores de la Unión Obrera Sindical "Río Florido" al Srio. de Educación Pública, ciudad Camargo, Chih., 1930. AGN, AHSEP, DE, caja 31029, exp. 11-7-10-183. 
espíritu, al chocarse con el del autor. El encanto de un libro es su valor de conversación, que es su vida. En cambio, su valor de doctrina, de dogma, de magisterio, es lo que suele morir en cuanto queda escrito. Lo principal es que un autor suscite en el lector sugestiones; esto es, respuestas, diálogo, conversación (Alomar, 1922: 96).

\section{Lectoras}

Otro aspecto importante de la modernización por medio de las bibliotecas es el que se daba en el seno de los grupos femeninos con la incorporación de las mujeres a la escena política. Como indica Kenya Bello en su análisis de las publicaciones femeninas del siglo XIX: "para que las lectoras disfrutaran del derecho a lo impreso no se registraron revueltas ni motines. La batalla se nutrió de desafíos minúsculos y cotidianos a los padres, al esposo, a los maestros" (Bello Baños, 2013). En el México posrevolucionario aún pervivían concepciones de los peligros de dejar leer ciertos libros a las mujeres; por ejemplo, novelas que les mostraran los vicios y crímenes de la sociedad. Cuál no sería la reacción ante otro tipo de lecturas, ya no las novelescas, sino de aquellos libros "socialistas" que tampoco encajaban dentro de la lectura "instructiva y moralizante", considerada por los sectores más conservadores el único tipo de lectura femenina deseable.

En consonancia con esas ideas moralistas, en 1927, el Círculo Minerva, una asociación cultural femenina (presidida por hombres) de la capital de Aguascalientes, solicitaba una biblioteca para llevar a cabo su principal labor: la difusión cultural, "dentro de su radio de actividades, aún cuando el mismo no es muy amplio". ${ }^{33}$ El círculo funcionaba mediante un sistema de cooperación mutua que les permitía impartir clases de inglés, literatura, música y gramática a niñas y jóvenes de distintas clases sociales. Contaba además con un semanario donde se daba impulso a la lectura, así como a la escritura, pues se publicaban artículos de las lectoras:

Con la ayuda de una compañía de señoritas, miembros todas ellas de este Círculo, las cuales editan un pequeño semanario de tendencias absolutamente morales y en el cual se ha procurado prestar toda clase de facilidades a las que bien por timidez, o bien por una modestia opresiva, nunca habían tenido ánimos para escribir públicamente..34

\footnotetext{
${ }^{33}$ Carta de Jesús L. Macías, presidente, y J. Bernal, secretario, al Jefe del Depto. de Bibliotecas, Aguascalientes, Ags., 6 de abril, 1927. AGN, AHSEP, DB, caja 31231, exp. 24-8-42-36.

${ }^{34}$ Ibid., caja 31231, exp. 24-8-42-36.
} 
La tendencia moral del semanario, de nombre Idea y acción, quedaba reflejada claramente en su lema: "Obra con rectitud, no te dejes arrastrar por tus pasiones". ${ }^{35}$ Con una suscripción semestral de 1.50 pesos, el semanario era dirigido exclusivamente por mujeres. Francisca Flores era la directora, las señoritas Guadalupe Díaz y Fausta Valdivia eran las agentes de redacción, y la mayoría de los artículos eran firmados por mujeres lectoras. Cabe mencionar que el proceso de participación femenina como redactoras, y no sólo como público receptor, se había consolidado en México entre 1873 y 1907,,36 por lo que este semanario era heredero de esa tradición. En cuanto a los temas abordados en el semanario, al menos en el número que enviaron a la SEP, se advierten no únicamente cuestiones domésticas tales como las obligaciones de los sexos (los roles de género), el matrimonio o la educación de los hijos - si bien había poemas que denunciaban el abandono progresivo de algunas tradiciones familiares, como el asistir a la iglesia-; los textos giran también en torno de experiencias escolares (una excursión al campo), poemas sobre la pérdida de algún familiar, prosas poéticas que exaltaban lo mismo a la naturaleza, como a la importancia de la escritura en la vida de alguna lectora. "A una amiga", un texto de una alumna de la Academia "Flores Rodríguez", era una composición dedicada a su máquina de escribir y a las ideas que le permitía plasmar:

Tú que sabes mis penas y alegrías, mis ilusiones y desesperanzas, porque a tus teclas lo he confiado todo [...] ¡No sé por qué se encariña la existencia con cosas tan materiales! ¡Oh, mi máquina! Yo te bendigo porque al monótono tictac de tus teclas has sabido despertar en mi corazón la esperanza y la alegría, has llenado de armonía el silencio de mi vida, despertaste mis dormidas ilusiones. ${ }^{37}$

Los textos de este semanario "no son una obra maestra en asuntos literarios; pero que nos dejan ver muy a las claras el esfuerzo que se ha hecho para llevar a cabo ideas sanas y nobles [...] donde familias enteras dedican unos minutos a la lectura de sus páginas", escribía en él otra de las lectoras, una antigua alumna de la misma academia. ${ }^{38}$ De esa forma, la "modestia opresiva" característica de las mujeres estaba cambiando, al menos en el atreverse a plasmar sus pensamientos por escrito. No obstante, estas mujeres todavía escribían pensando con los referentes impuestos por la cultura en la que vivían inmersas: como

\footnotetext{
${ }^{35}$ Idea y acción. Semanario Regional de Literatura, Información y Variedades. Tomo I, núm. 51. Aguascalientes, Ags., 28 de marzo, 1927. AGN, AHSEP, DB, caja 31231, exp. 24-8-42-36.

${ }^{36}$ Sobre la participación de las mujeres en empresas editoriales durante el siglo XIX, véase Bello Baños (2007) e Infante Vargas (2005).

37 "A una amiga", Idea y acción, p. 7. Ibid., caja 31231, exp. 24-8-8-42-36.

38 "Un año de vida", Idea y acción, p. 4. Ibid., caja 31231, exp. 24-8-8-42-36.
} 
alumnas que se estaban preparando para ser madres o esposas, como las encargadas de transmitir una educación temprana a sus hijos, y tal vez no más.

Otra era la situación de las mujeres que se desempeñaban en ámbitos laborales fuera del hogar, en fábricas, en molinos, en mercados, y que, poco a poco, iban sentando las bases para una transformación en los roles tradicionales de género.

En el México posrevolucionario, con la construcción de un nuevo aparato estatal, el conflicto Iglesia-Estado y el surgimiento de un movimiento obrero organizado, se dieron las condiciones para que en algunas regiones del país las mujeres se politizaran y adquirieran un papel más activo en la esfera pública (Fernández-Aceves, 2010). Las mujeres pertenecientes a los sindicatos de obreras que solicitaban libros a la SEP lo hacían, si bien en los términos propios del discurso estatal paternalista, con un interés menor en lo literario o educativo y, en cambio, estaban más preocupadas por aprender a organizarse y luchar por sus derechos, tal como lo venían haciendo sus compañeros del sexo masculino.

Esto puede notarse en la solicitud del Sindicato de Obreras Desmanchadoras de Café, en Córdoba, Veracruz. Hermelinda Vera, la secretaria general, solicitaba "libros modernos" a Esperanza Velázquez Bringas, en 1926: "Solicitando un lote de libros para instalar nuestra Biblioteca, donde permita a las coasociadas de este Sindicato, instruirse leyendo libros modernos, es decir, escritos por autores socialistas, y de esa manera acrecentar la lucha social que hemos emprendido con tanto tezón". ${ }^{39}$ Algunos de los títulos que recibieron estas obreras, además de unas tres obras de los clásicos, eran El problema agrario de México, El General Calles y el sindicalismo, Cooperativas en México, y La evolución política de Ibero-América. Las ideas socialistas que se propagaban estaban bajo el auspicio de un Estado que buscaba, ante todo, tener el control sobre los diversos movimientos y organizaciones obreras.

Fowler-Salamini (2010), quien analizó las formas de organización y agencia de las desmanchadoras de café veracruzanas de la década de 1920, incluidas las de Córdoba, señala el cambio en las percepciones de estas mujeres sobre su rol como amas de casa. Para ellas "el mejor marido [era] el trabajo". Estas mujeres quisieron "pasar a la historia como supermujeres, mujeres que podían llevar a casa el dinero de la quincena y ser también esposas y madres responsables. Para racionalizar los dos roles, solían llamarse 'madronas' entre ellas, mujeres de carácter fuerte que, igual que los hombres, no querían ser contrariadas" (FowlerSalamini, 2010: 274). En ese sentido, es que las mujeres trabajadoras adoptaron también el lenguaje normalmente asociado al del sindicalismo obrero masculino y no entonces como las tradicionales amas de casa.

${ }^{39}$ Carta de Hermelinda Vera a Esperanza Velázquez Bringas, Córdoba, Ver., 27 de enero, 1926. AGN, AHSEP, DB, caja 31163, exp. 24-8-30-115, f. 2. 


\section{Consideraciones finales}

La producción editorial de la SEP fue cambiando de 1921 a 1934. Pasó de la propuesta vasconcelista integral de la lectura en sus diferentes niveles - con diversidad de textos (literatura clásica, literatura infantil, así como con la adquisición de libros escolares y manuales para formar bibliotecas) - a un abandono progresivo de la publicación de libros en favor de folletos que propiciaran una lectura más sencilla, práctica y de utilidad para la vida campesina en el medio rural o de la organización sindical en la ciudad.

Una perspectiva más general de esta política, sin embargo, pareciera indicarnos que, con sus variaciones, estamos ante un proyecto de construcción de Estado interesado en dar a obreros, maestros, campesinos e indígenas nociones de sus derechos y obligaciones para con el mismo Estado en formación. La decisión de Vasconcelos de no incluir en el programa editorial obras de "política militante", y en cambio enfocarse en la publicación de literatura parece ser una simple condescendencia. A la élite política le convenía retomar el poder de la palabra escrita, y su difusión por el medio editorial, para la caracterización de la situación y necesidades de obreros y campesinos que justificara la intervención civilizatoria del Estado. Discurso más patente en las publicaciones de la SEP a partir de 1928 con los folletos-silabarios, y que logra una mejor cohesión en 1932 con la revista El Maestro Rural.

Con todo, la lectura es una actividad creativa y difícil de controlar y las respuestas de los lectores fueron variadas y no siempre estuvieron en consonancia con los intereses estatales. Aunque una tendencia fuerte en las solicitudes de libros aquí analizadas fue la de una adecuación al discurso estatal de la lectura útil, en las peticiones de otros lectores sobresale una noción de complementariedad: lecturas prácticas para desempeñar mejor sus labores pero también lecturas que satisficieran un anhelo de desarrollo intelectual, pues no consideraban que el objetivo de una persona en la vida fuera "trabajar únicamente como una bestia humana, ni que las Sociedades persigan únicamente fines socialistas", como lo expresaron los ferrocarrileros de San Luis Potosí al pragmático Secretario de Educación, Ezequiel Padilla. Asimismo, era importante para otros grupos e individuos desarrollar de manera gradual el gusto por la lectura de obras más complejas, un tema al que la SEP no le dio el suficiente impulso. Por otra parte, algunos trabajadores solicitaban los clásicos, como una forma de distinguirse socialmente de otros grupos que no sabían valorar la literatura o bien simplemente atendiendo al placer de la lectura.

En cuanto a las agrupaciones femeninas que solicitaban libros, su interés en la lectura dependía bastante de la pertenencia socioprofesional. Es decir, para las mujeres obreras, comerciantes o agricultoras una preocupación constante fue la de aprender a organizarse para luchar por sus derechos, tal como veían que empezaban a hacerlo sus compañeros varones. Los libros sobre temas sociales, de derecho y "sociología", eran entonces los más 
demandados. En cambio, las sociedades femeninas alejadas de ese tipo de actividades laborales estaban más preocupadas por establecer una educación moral a partir de la lectura, una caracterización muy parecida a la lectura femenina en el siglo XIX.

Sin duda, esta tipificación que presento no es más que una posible interpretación entre muchas. Más que encasillar a un grupo en una sola posibilidad de lectura, la clasificación realizada se refiere a las disposiciones que fueron expresadas en un momento determinado. No obstante, la lectura, como la educación, tiene al menos una doble función —disciplinante y emancipadora- que puede entreverse en las palabras de los lectores. En su reclamo de libros, si bien en algunos casos los lectores y las lectoras asumieron los objetivos de la SEP, también mostraron su capacidad de adaptar o modificar las propuestas recibidas o solicitar otras diferentes siguiendo sus propios intereses, aspiraciones o deseos. Como ha venido demostrando la historiografía de la educación que atiende no únicamente a las normas de los "productores", los "receptores" no eran aquellos sujetos fácilmente moldeables imaginados por los diseñadores de políticas.

\section{Fuentes}

Archivos

Archivo General de la Nación, Archivo Histórico de la Secretaría de Educación Pública, México Fondo: Departamento de Bibliotecas y Departamento Editorial (AGN, AHSEP, DB).

Bibliografía

Aguirre, Mario (2002), Revista El Maestro (1921-1923): raíces y vuelos de la propuesta educativa vasconcelista, Universidad Pedagógica Nacional-Porrúa, México.

Alomar, Gabriel (1922), "Las normas de la autodidáctica", El Libro y el Pueblo, t. 1, núm. 8, octubre, pp. 95-96.

Bahloul, Joëlle (2013), Lecturas precarias. Estudio sociológico sobre los "poco lectores", Fondo de Cultura Económica, México.

Barbosa, Antonio (1972), Cien años en la educación de México, PAX, México.

Bello, Kenya (2013), "Un anzuelo para señoritas lectoras", Revista Letras Libres, edición electrónica, noviembre, documento html disponible en: <www.letraslibres.com/mexico-espana/un-anzuelo-senoritas-lectoras>, (fecha de consulta: 30/08/2016).

Bello, Kenya (2007), "La educación sentimental. Editoras y lectoras porfirianas de la ciudad de México en El Periódico de las Señoras (1896)” tesis de maestría, Instituto de Investigaciones Dr. José María Luis Mora, México.

Chartier, Roger (2000), El orden de los libros. Lectores, autores, bibliotecas en Europa entre los siglos XIV y XVIII, Gedisa, Barcelona.

Chartier, Roger (1994), "De la historia del libro a la historia de la lectura", en Roger Chartier, Libros, lecturas y lectores en la Edad Moderna, Alianza Universidad, Madrid. 
Curiel, Fernando (2011), "Letras, libros. La cruzada impresora de Vasconcelos", en Jaime Ríos y César Ramírez (coords.), Procesos revolucionarios, bibliotecas y movimientos culturales, Universidad Nacional Autónoma de México, México.

Elias, Norbert (2012), El proceso de la civilización. Investigaciones sociogenéticas y psicogenéticas, Fondo de Cultura Económica, México.

Fell, Claude (2009), José Vasconcelos: Los años del águila (1920-1925). Educación, cultura e iberoamericanismo en el México posrevolucionario, Universidad Nacional Autónoma de México, México.

Fernández-Aceves, María (2010), "La lucha entre el metate y el molino de nixtamal en Guadalajara, 1920-1940", en Gabriela Cano; Mary Kay Vaughan y Jocelyn Olcott (coords.), Género, poder y política en el México posrevolucionario, Fondo de Cultura Económica, México.

Fowler-Salamini, Heather (2010), "Género, trabajo, sindicalismo y cultura de las mujeres de la clase trabajadora en el Veracruz posrevolucionario" en Gabriela Cano, Mary Kay Vaughan y Jocelyn Olcott (coords.), Género, poder y política en el México posrevolucionario, Fondo de Cultura Económica, México.

Gamio, Manuel (1925), "Los libros útiles para México", El Libro y el Pueblo, t. 4, núm. 6, abril-junio, pp. 14-17.

Garciadiego, Javier (2011), "Vasconcelos y los libros: editor y bibliotecario" en Rebeca Barriga (coord.), Entre paradojas: A 50 años de los libros de texto gratuitos, El Colegio de México-Secretaría de Educación Pública-Comisión Nacional de Libros de Texto Gratuitos, México.

Giraudo, Laura (2004), "Lectores campesinos, maestros indígenas y bibliotecas rurales. Puebla y Veracruz, 1920-1930”, en Carmen Castañeda, Luz Elena Galván y Lucía Martínez (coords.), Lecturas y lectores en la historia de México, Centro de Investigaciones y Estudios Superiores en Antropología Social-El Colegio de Michoacán-Universidad Autónoma del Estado de México, México, pp. 303-326.

Infante, Lucrecia (2005), "De lectoras y redactoras. Las publicaciones femeninas en México durante el siglo XIX", en Belem Clark y Elisa Speckman (coords.), La República de las letras: asomos a la cultura escrita del México decimonónico, vol. I, II y III, Universidad Nacional Autónoma de México, México.

Loyo, Engracia (2012), "En el aula y la parcela: vida escolar en el medio rural (1921-1940)", en Aurelio de los Reyes (coord.), Historia de la vida cotidiana en México, t. v., vol. 1, Siglo Xx. Campo y ciudad, Fondo de Cultura Económica-El Colegio de México, México, pp. 273-312.

Loyo, Engracia (2004), "La formación de un público lector: El Libro y el Pueblo, 1922-1935", en Carmen Castañeda, Luz Elena Galván y Lucía Martínez (coords.), Lecturas y lectores en la historia de México, Centro de Investigaciones y Estudios Superiores en Antropología Social-El Colegio de MichoacánUniversidad Autónoma del Estado de México, México, pp. 359-370.

Loyo, Engracia (1999), "La lectura en México, 1920-1940", en Josefina Zoraida Vázquez (coord.), Historia de la lectura en México, El Colegio de México, México, pp. 243-270.

Manguel, Alberto (2011), "Cómo aprendió a leer Pinocho", en Alberto Manguel, Lecturas sobre la lectura, Océano Travesía, Barcelona.

Manguel, Alberto (2005), Una historia de la lectura, Alianza Editorial, Madrid.

Montes de Oca, Elvira (2004), "Las mujeres lectoras en la década de 1920", en Carmen Castañeda, Luz Elena Galván y Lucía Martínez (coords.), Lecturas y lectores en la historia de México, Centro de Investigaciones y Estudios Superiores en Antropología Social-El Colegio de Michoacán-Universidad Autónoma del Estado de México, México, pp. 285-302.

Padilla, Ezequiel (1928), La educación del pueblo: discursos, Herrero Hermanos, México.

Palacios, Guillermo (1999), La pluma y el arado. Los intelectuales pedagogos y la construcción sociocultural del "problema campesino" en México, 1932-1934, El Colegio de México-Centro de Investigación y Docencia Económicas, México. 
Peroni, Michel (2003), Historias de lectura. Trayectorias de vida y de lectura, Fondo de Cultura Económica, México.

Quintana, Guadalupe, Cristina Villegas y Guadalupe Tolosa (1988), Las bibliotecas públicas en México: 1910-1940, Secretaría de Educación Pública, México

Quintanilla, Susana (2002), "Dionisio en México o cómo leyeron nuestros clásicos a los clásicos griegos", Historia Mexicana, vol. 51, núm. 3, enero-marzo, pp. 619-663, documento pdf disponible en: <www. redalyc.org/pdf/600/60051304.pdf> (fecha de consulta: 05/02/2016).

Rockwell, Elsie (2004), "Entre la vida y los libros. Prácticas de lectura en las escuelas de la Malintzi a principios del siglo xx", en Carmen Castañeda, Luz Elena Galván y Lucía Martínez (coords.), Lecturas y lectores en la historia de México, Centro de Investigaciones y Estudios Superiores en Antropología Social-El Colegio de Michoacán-Universidad Autónoma del Estado de México, México, pp. 327-357.

Rockwell, Elsie (2001), "La lectura como práctica cultural: conceptos para el estudio de los libros escolares", Educação e Pesquisa, núm. 27, enero-junio, documento html disponible en: <www.scielo.br/ scielo.php?script=sci_arttext\&pid=S151797022001000100002\&lng=en\&nrm=iso\& \&lng=es> (fecha de consulta: 29/05/2016).

Rodríguez, Adolfo (2015), José Vasconcelos: alfabetización, bibliotecas, lectura y edición, Universidad Nacional Autónoma de México, México.

Ruíz, Verónica (2013), "El Maestro Rural y la Revista de Educación. El sueño de transformar el país desde la editorial", Signos Históricos, núm. 29, enero-junio, pp. 36-63, documento pdf disponible en: <www.redalyc.org/articulo.oa?id=34428269002> (fecha de consulta: 20/10/2014).

Sametz, Linda (2009), Vasconcelos, el hombre del libro: creador del primer sistema de bibliotecas, Consejo Nacional para la Cultura y las Artes, México.

Vasconcelos, José (2009) [1935], De Robinson a Odiseo. Pedagogía estructurativa, Trillas, México.

Vaughan, Mary Kay (1997), "Cambio ideológico en la política educativa de la SEP: programas y libros de texto, 1921-1940", en Susana Quintanilla y Mary Kay Vaughan (coords.), Escuela y sociedad en el periodo cardenista, Fondo de Cultura Económica, México, pp. 76-108.

Francisco Javier Rosales Morales. Estudiante del programa de Maestría en Ciencias con especialidad en Investigaciones Educativas del DIE-Cinvestav. Licenciado en sociología. Líneas de investigación: historia del libro y la lectura, México posrevolucionario.

Recibido: 13 de octubre de 2016

Aceptado: 15 de noviembre de 2016 